\title{
Co-Deposition of Gold and Magnetite Nanoparticles onto Pinnularia sp. Diatom Frustules
}

\author{
Haiyan $\mathrm{Li}^{1}$, Sarah Wong ${ }^{2}$, Walter Hudson ${ }^{1}$, Jun Jiao ${ }^{1 *}$ \\ ${ }^{1}$ Department of Physics, Portland State University, Portland, OR 97207 \\ ${ }^{2}$ Department of Chemical Engineering, Oregon State University, Corvallis, OR 97331 \\ *jiaoj@pdx.edu
}

Diatoms are a prolific class of unicellular photosynthetic algae with intricate silica shells [1]. The diatom frustules are capable of light coherence through their periodic patterned-biosilica [2]. Furthermore, the biosilica structures of the diatoms are genetically controlled and highly reproducible [3]. A number of studies suggest that diatom frustules are promising templates for the fabrication of photonic structures with various chemical compositions on a large scale and with low cost [4,5]. To further advance this investigation, we report here the decoration of Pinnularia sp. diatom frustules with both high crystalline $\mathrm{Au}$ and $\mathrm{Fe}_{3} \mathrm{O}_{4}$ nanoparticles (NPs) through a solvothermal procedure.

We used Au NPs to decorate the diatom frustules aimed at taking advantage of the fact that light adsorption resulted from the Au-NPs' surface plasmon resonance effect. Typically, Au NPs were deposited onto the diatom frustules by solvothermal reaction in a Teflon-lined autoclave at $185^{\circ} \mathrm{C}$ for 12 h. The precursors consisted of $0.05 \mathrm{mmol} \mathrm{AuCl}_{4}, 0.15 \mathrm{mmol}$ cetyltrimethylammonium bromide (CTAB), $2 \mathrm{~mL}$ oleyamine and $30 \mathrm{mg}$ of the diatom frustules in $15 \mathrm{~mL}$ of ethanol. The products were characterized by a FEI Sirion Field Emission Scanning Electron Microscope (FE-SEM) and a FEI Tecnai F-20 Transmission Electron Microscope (TEM). As shown in Figure a and b, the bare Pinnularia sp. diatom frustules possessed a bilaterally symmetric, pinnate and intricate porous structure. The length and width of the diatom frustules were about $30 \mu \mathrm{m}$ and $5 \mu \mathrm{m}$, respectively. The biosilica pores have diameters around $200-250 \mathrm{~nm}$ and the spacing between them is approximately $60-100 \mathrm{~nm}$. Also note that thin and porous biosilica films were lined in each pore of the array. After the solvothermal treatment, TEM analysis indicated that Au NPs were grown on the pore edges of the diatom frustules (Figure c). It is reasoned that the growth of Au NPs preferred to occur on the thin biosilica film lined in the pore rather than on the thick biosilica frames. The fragile film was then broken during the reaction. This resulted in the deposition of Au NPs near the pore edge only. The size of the deposited Au NPs ranged from 20 to 50 $\mathrm{nm}$. High resolution TEM (HRTEM) revealed that as-deposited Au NPs onto the diatom frustules were dodecagonal quasi-crystalline structures (Figure d). Next, we fabricated hybrid bi-functional periodic biosilica/Au/Magnetite $\left(\mathrm{Fe}_{3} \mathrm{O}_{4}\right) \mathrm{NP}$ structures using a similar solvothermal method. The precursor consisted of $0.05 \mathrm{mmol} \mathrm{AuCl}_{4}, 0.02 \mathrm{mmol}$ iron (III) acetylacetonate, $0.15 \mathrm{mmol} \mathrm{CTAB}, 2 \mathrm{~mL}$ oleyamine and $30 \mathrm{mg}$ of the diatom frustules in $15 \mathrm{~mL}$ of ethanol. As shown in Figure e, similar to the previous products, both $\mathrm{Au}$ and $\mathrm{Fe}_{3} \mathrm{O}_{4} \mathrm{NPs}$ were successfully deposited near the pore edge of the frustules. HRTEM imaging exhibited that both the $\mathrm{Au}$ and $\mathrm{Fe}_{3} \mathrm{O}_{4} \mathrm{NPs}$ were crystalline (Figure f). Compared to the $\mathrm{Au}$ NPs, the $\mathrm{Fe}_{3} \mathrm{O}_{4}$ NPs are much smaller being about 5-10 nm in diameter.

In summary, we successfully co-deposited $\mathrm{Au}$ and $\mathrm{Fe}_{3} \mathrm{O}_{4} \mathrm{NPs}$ onto diatom frustules. Further optimizing the demonstrated process will result in a series of biosilica/ $\mathrm{Au} / \mathrm{Fe}_{3} \mathrm{O}_{4} \mathrm{NPs}$ hybrid materials with both tunable light absorption and magnetic properties.

\section{References}

[1] Vukusic, P. and Sambles, J. R. Photonic structures in biology. Nature 2003, 424:852-855

[2] Yamanaka, S.; Yano, R.; Hisanao, U.; Hayashida, N.; Ohguchi, M.; Takeda, H. and Yoshino, K. Optical properties of diatom silica frustule with special reference to blue light. J. Appl. Phys. 2008, 103:074701

[3] Round, F. E., Craford, R. M., Man, D. G. The diatoms. Cambridge University Press 1990 
[4] Yu, Y.; Jonas, A.; Dusan, L. Synthesis of self-supporting gold microstructures with three-dimensional morphologies by direct replication of diatom templates. Langmuir 2010, 26:14068-14072

[5] Losic, D.; Mitchell, J. G.; Voelcker, N. H. Fabrication of gold nanostructures by templating from porous diatom frustules. New J. Chem. 2006, 30:908-914
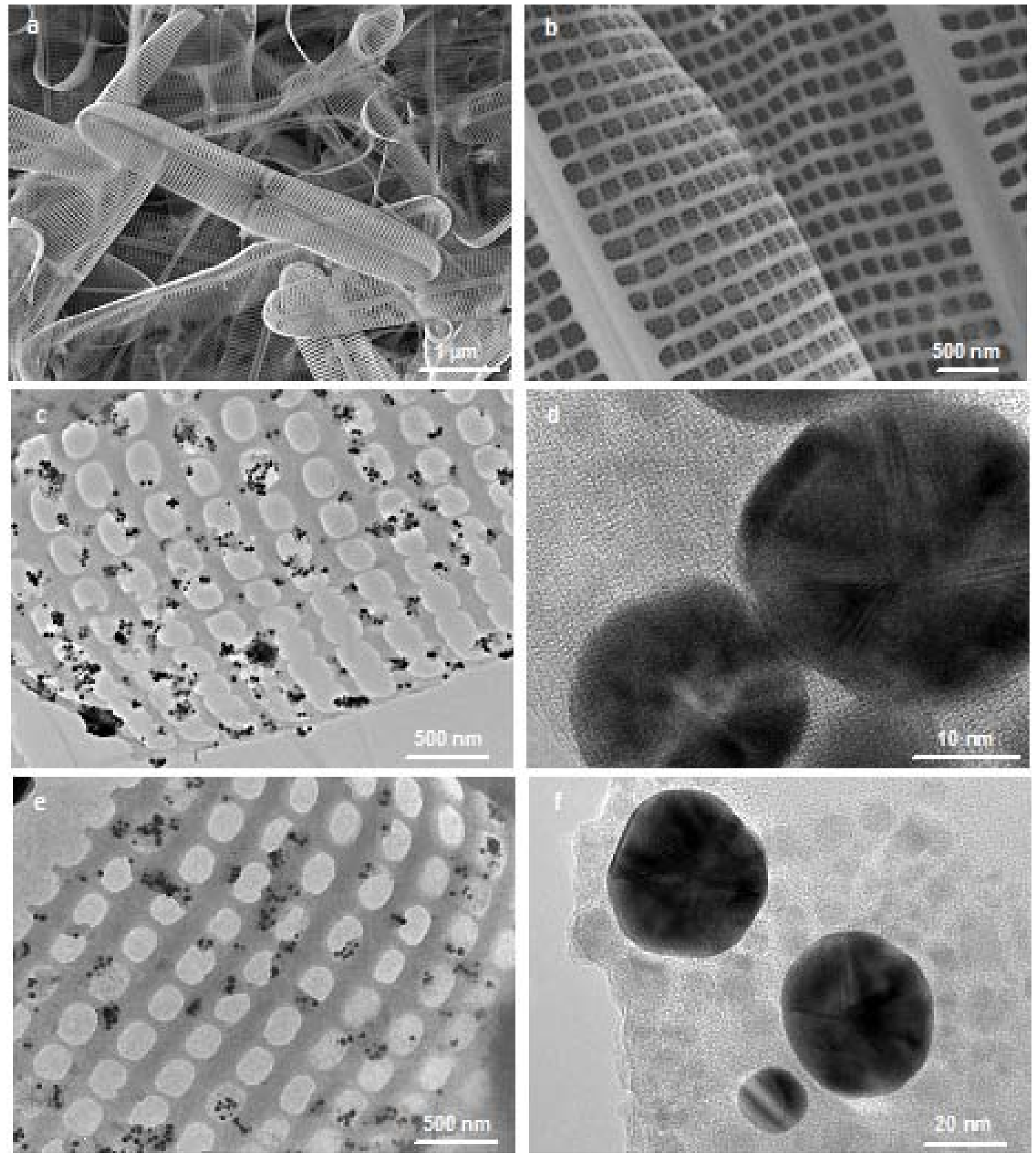

Figure a SEM image of diatom frustules. Figure b High resolution SEM image of a diatom frustule showing the fine structure of the pore array. Figure c TEM image of Au NP-decorated diatom frustules. Figure d HRTEM image of as-synthesized Au NPs on the diatom frustule. Figure e TEM image of Au $\mathrm{NP} / \mathrm{Fe}_{3} \mathrm{O}_{4} \mathrm{NP}$-co-decorated diatom frustules. Figure $\mathbf{f}$ HRTEM image of as-synthesized Au NPs and $\mathrm{Fe}_{3} \mathrm{O}_{4}$ NPs (the contrast is lower than that of Au NPs) on the diatom frustule. 